\title{
Suicide Screening in the Oncology Population
}

MARY K. HUGHES, MS, RN, CNS, CT

From The University of Texas MD Anderson Cancer Center, Houston, Texas

Author's disclosures of potential conflicts of interest are found at the end of this article. Correspondence to: Mary K. Hughes, MS, RN, CNS, CT, MD Anderson Cancer Center, 1400 Pressler, Unit 1454, Houston, TX 77230.E-mail:mhughes@ mdanderson.org

doi: 10.6004/jadpro.2016.7.1.9

(c) 2016 Harborside Press ${ }^{\circledR}$
J Adv Pract Oncol 2016;7:101-104

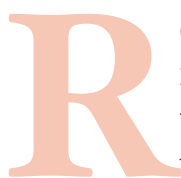

egistered nurses spend more time with patients than other health-care workers and are in a prime position to detect and prevent suicidal behaviors in patients, but Valente (2010) found that oncology nurses had more difficulty in caring for suicidal patients because of their commitment to preserving life. Although a relatively rare event, suicide increases in patients with the diagnosis of cancer (Misono, Weiss, Fann, Redman, \& Yueh, 2008). Shneidman (1985) defined suicide as "the conscious act of self-induced annihilation, best understood as a multidimensional malaise in a needful individual who defines an issue for which the act is perceived as the best solution." It is not random or pointless but a release from an issue or crisis that produces intense suffering (Kaplan \& Sadock, 1998).

The most common mental illness found in cancer-related suicide cases is depression (75\%; de la Grandmaison, Watier, Cavard, \& Charlier, 2014). The prevalence of depression among patients with cancer is between $5 \%$ and $16 \%$ (Walker et al., 2013). Since fatigue and depression occur concurrently, fatigue can be a cue for practitioners to investigate for depression (Rhondali et al., 2012). Multiple studies have identified a higher risk factor for suicide during the first months after a cancer diagnosis as well as 1 year after (Anguiano, Mayer, Piven, \& Rosenstein, 2012).

\section{PATIENTS AT RISK}

Who is more vulnerable to suicide after a cancer diagnosis? There are four site-specific malignancies with higher suicide rates than other sites: the head and neck, lungs, pancreas, and prostate (Lydiatt, Moran, \& Burke, 2009; Urban et al., 2013; Carlsson et al., 2013; Miller, Mogun, Azrael, Hempstead, \& Solomon, 2008; Turaga, Malafa, Jacobsen, Schell, \& Sarr, 2011). Men with testicular cancer have a 20\% increase in the risk of suicide over that of the general population (Alanee \& Russo, 2012). Klaassen et al. (2015) found that patients with bladder cancer posed the highest risk for suicide within the first 5 years after diagnosis. Mohammadi and colleagues (2014) found that patients with myeloma had the highest rate of attempted as well as completed suicide of those with hematologic malignancies.

Adult survivors of childhood cancers have higher suicidality (Recklitis et al., 2010). Other risk factors for suicide include being male or being over 65 (Anguiano et al., 2012). 
Women with gynecologic cancer, especially ovarian, have a higher incidence of suicide than women with other cancers (Ward, Roncancio, \& Plaxe, 2012; Tang et al., 2015).

Clinical factors associated with suicidality include substantial pain, insomnia, fatigue, loss of autonomy and independence, poor social support, impaired physical functioning, demoralization, and emotional distress (de la Grandmaison et al., 2014; Fang et al., 2014). It is important to have effective symptom management so patients do not suffer needlessly.

A powerful predictor of suicide ideation and completed suicide is hopelessness (Abbey, Rosenfeld, Pessin, \& Breitbart, 2006). Surprisingly, suicide in the general population is most significantly associated with risky behavior, psychomotor agitation, and impulsivity, which can be associated with mixed depression (Harrison, 2015), where the patient is depressed but also has symptoms of excitation. Table 1 lists some of the warning signs of suicide.

\section{ASSESSMENT}

Assessment for suicide should occur frequently along the cancer continuum. Advanced practitioners are in an ideal position to add this type of screening into their patient encounters. Compo-

\section{Table 1. Warning Signs of Suicide}

- Talking about wanting to die or to kill oneself

- Looking for a way to kill oneself, such as searching online or buying a gun

- Talking about feeling hopeless or having no reason to live

- Talking about feeling trapped or in unbearable pain

- Talking about being a burden to others

- Increasing use of alcohol or drugs

- Acting anxious or agitated; behaving recklessly

- Sleeping too much or too little

- Withdrawing or feeling isolated

- Showing rage or talking about seeking revenge

- Displaying extreme mood swings

- Reporting command auditory hallucinations to harm self or others

- Evidence of persecutory delusions

Note. Information from Trzepacz \& Baker (1993). nents should include patient and family histories of suicide, suicidal attempts, psychiatric disorders (especially depression), as well as a history of drug or alcohol use or abuse (Aiello-Laws, 2010). There are no reliable screening tools to help prevent suicide in cancer populations, but there are reliable screening tools to detect depression: the Beck Hopelessness Scale; Diagnostic and Statistical Manual of Mental Disorders, Fifth Edition criteria; Patient Health Questionnaire; Endicott criteria using the Hamilton Depression Rating Scale; and simply asking, "Are you depressed?" (Anguiano et al., 2012). Asking this question will not put the idea into a patient's head. When asked that question, most patients adamantly deny wanting to harm themselves. If these patients are so distressed to have suicidal thoughts, they affirm these thoughts. Kissane et al. (2004) developed a Demoralization Scale, which can also predict suicidality.

The National Comprehensive Cancer Network (NCCN) introduced the Distress Thermometer for use by patients and clinicians. The NCCN (2015) uses the word distress rather than depression to avoid any stigma and to facilitate discussion. The tool uses a visual thermometer, ranging from 0 for no distress and 10 indicating extreme distress; it consists of 36 yes/no questions. Scores of 4 or higher indicate clinically significant depressive symptoms (Ransom, Jacobsen, \& Booth-Jones, 2006).

There is a suicide risk assessment tool designed for non-mental health professionals to use for patients (Patterson, Dohn, Bird, \& Patterson, 1983). It goes by the acronym SAD PERSONS (Table 2) and assigns 1 point to each of 10 items. A score from 7 to 10 indicates that the person is at high risk for attempting suicide.

Suicide ideation includes serious thoughts, verbalizations, or behavioral indications about a possible attempted suicide. The source of the information can be the patient or an observer. If there is concern about suicide risk, patients should be asked about their access to lethal means, such as a gun in the house or unused bottles of medications (Aiello-Laws, 2010). If the concern is more immediate, patients should be assessed for a plan and method and the method removed. Other steps include ensuring a safe environment and staying with the patient, either on the phone or in person; 


\section{Table 2. Suicide Risk Assessment Tool}

Sex (male)

Age younger than 19 or older than 45 years

Depression (patient admits to depressive symptoms)

Previous suicide attempt or psychiatric care

Excessive alcohol or drug use

Rational thinking loss

Separated, divorced, or widowed

Organized plan or serious attempt

No social support

Sickness, chronic disease

as well as assessing social supports and mobilizing as much of their support system as possible and alerting the health-care team. Suicidal remarks, gestures, or self-destructive comments and/or behaviors should be documented in the patient's medical record.

Suicide precautions include actions implemented, such as patient observation, evaluation of the immediate physical environment, and implementation of physician directives. Suicide precautions should be instituted immediately and patients should be referred to appropriate resources (Valente, 2010; NCCN, 2015). Patients should be provided with a crisis hotline number (Lifeline: 1-800-273-TALK [8255]).

If the patient is in the hospital, call a security officer. Find out whether you need to write an order for one-to-one constant observation for safety. If the patient is in the clinic and there is inadequate staff or assistance to monitor and control the patient's behavior, call 911. If the patient is at home, ask a family member to bring the patient to the clinic or emergency department. If no one can do so, call 911 to take the patient to the nearest emergency department (Roth \& Levenson, 2015). Since this can be a life or death situation, family members can be notified without fear of violating HIPAA (Health Insurance Portability and Accountability Act) legislation. Table 3 offers a list of resources about suicide for advanced practitioners.

\section{SAVING LIVES THROUGH PREVENTION}

The goal of suicide prevention is to stop suicide attempts. As advanced practitioners are with

\section{Table 3. Resources About Suicide for Advanced} Practitioners

American Foundation for Suicide Prevention

www.afsp.org

American Psychiatric Nurses Association

www.apna.org

American Society of Suicidology

www.suicidology.org

Applied Suicide Intervention Skills Training

2-day workshop for caregivers to improve competence in helping to prevent the immediate risk of suicide

www.livingworks.net/

International Society of Psychiatric-Mental Health Nurses www.ispn-psych.org

\section{Means Matter}

www.hsph.harvard.edu/means-matter

National Institute of Mental Health

www.nimh.nih.gov

National Mental Health Awareness Campaign (NoStigmas) www.nostigmas.org

Question, Persuade, Refer for Nurses

www.sprc.org/bpr/section-III/question-persuade-referqpr-nurses

SPRC/AFSP Best Practices Registry for Suicide Prevention www.sprc.org/bpr

Substance Abuse and Mental Health Services

Administration

www.samhsa.gov; www.suicidepreventionlifeline.org

Suicide Anonymous

www.suicideanonymous.net

Suicide Prevention Advocacy Network

www.spanusa.org

Suicide Prevention Resource Center

www.sprc.org

Surgeon General's Call to Action to Prevent Suicide

www.surgeongeneral.gov/library/calltoaction/default.htm

patients more than any other health-care worker, their role is vital in preventing suicide. The goal of intervention is to work with patients to improve coping skills, reshape negative thoughts, and mobilize a support system while developing and maintaining a supportive alliance (Aiello-Laws, 2010). According to Chochinov (2001), the most effective intervention for depression is medication combined with psychosocial support and counseling. An apathetic attitude toward suicidality can be lethal. According to Bolster, Holliday, Oneal, and Shaw (2015), as more advanced practitioners are trained in suicide prevention, more lives can be saved. 


\section{Disclosure}

The author has no potential conflicts of interest to disclose.

\section{References}

Abbey, J., Rosenfeld, B., Pessin, H., \& Breitbart, W. (2006). Hopelessness at the end of life: The utility of the hopelessness scale with terminally ill cancer patients. British Journal of Health Psychology, 11(Pt 2), 173-183. http:// dx.doi.org/10.1348/135910705X36749

Aiello-Laws, L. B. (2010). Assessing the risk for suicide in patients with cancer. Clinical Journal of Oncology Nursing, 14, 687-691. http://dx.doi.org/10.1188/10.CJON.687-691

Alanee, S., \& Russo, P. (2012). Suicide in men with testis cancer. European Journal of Cancer Care, 21, 817-821. http:// dx.doi.org/10.1111/j.1365-2354.2012.01366.x

Anguiano, L., Mayer, D. K., Piven, M. L., \& Rosenstein, D. (2012). A literature review of suicide in cancer patients. Cancer Nursing, 35, E14-E26. http://dx.doi.org/10.1097/ NCC.0b013e31822fc76c

Bolster, C., Holliday, C., Oneal, G., \& Shaw, M. (2015). Suicide assessment and nurses: What does the evidence show? The Online Journal of Issues in Nursing, 20(1). Retrieved from http://www.medscape.com/viewarticle/847034

Carlsson, S., Sandin, F., Fall, K., Lambe, M., Adolfsson, J., Stattin, P.,...Bill-Axelson, A. (2013). Risk of suicide in men with low-risk prostate cancer. European Journal of Cancer, 49, 1588-1599. http://dx.doi.org/10.1016/j. ejca.2012.12.018

Chochinov, H. M. (2001). Depression in cancer patients. The Lancet Oncology, 2, 499-505. http://dx.doi.org/10.1016/ S1470-2045(01)00456-9

de la Grandmaison, G. L., Watier, L., Cavard, S., \& Charlier, P. (2014). Are suicide rates higher in the cancer population? An investigation using forensic autopsy data. Medical Hypotheses, 82, 16-19. http://dx.doi.org/10.1016/j. mehy.2013.10.025

Fang, C. K., Chang, M. C., Chen P. J., Lin, C. C., Chen, G. S., Lin, J.,...Li, Y. C. (2014). A correlational study of suicidal ideation with psychological distress, depression, and demoralization in patients with cancer. Supportive Care in Cancer, 22, 3165-3174. http://dx.doi.org/10.1007/s00520014-2290-4

Harrison, P. (2015). Risk factors for suicide identified in BRIDGE-II-MIX study. Retrieved from http://www. medscape.com/viewarticle/850297

Kaplan, H., \& Sadock, B. (1998). Emergency psychiatric medicine. In Synopsis of Psychiatry (8th Ed, p 897). Philadelphia, PA: Lippincott Williams \& Wilkins.

Kissane, D. W., Wein, S., Love, A., Lee, X. Q., Kee, P. L., \& Clarke, D. M. (2004). The Demoralization Scale: A report of its development and preliminary validation. Journal of Palliative Care, 20, 269-276.

Klaassen, Z., Jen, R. P., DiBianco, J. M., Reinstatler, L., Li, Q., Madi, R.,...Terris, M. K. (2015). Factors associated with suicide in patients with genitourinary malignancies. Cancer, 121, 1864-1872. http://dx.doi.org/10.1002/ cncr.29274

Lydiatt, W. M., Moran, J., \& Burke, W. J. (2009). A review of depression in the head and neck cancer patient. Clinical Advances in Hematology and Oncology, 7, 397-403.

Miller, M., Mogun, H., Azrael, D., Hempstead, K., \& Solomon, D. H. (2008). Cancer and the risk of suicide in older Americans. American Journal of Geriatric Psychiatry, 13, 195-201. http://dx.doi.org/10.1200/jco.2007.14.3990

Misono, S., Weiss, N. S, Fann, J. R., Redman, M., \& Yueh, B.
(2008). Incidence of suicide in persons with cancer. Journal of Clinical Oncology, 26, 4731-4738. http://dx.doi. org/10.1200/JCO.2007.13.8941

Mohammadi, M., Moradi, T., Bottai, M., Reutfors, J., Cao, Y., \& Smedby, K. E. (2014). Risk and predictors of attempted and completed suicide in patients with hematological malignancies. Psycho-Oncology, 23, 1276-1282. http:// dx.doi.org/10.1002/pon.3561

National Comprehensive Cancer Network. (2015). NCCN Clinical Practice Guidelines in Oncology: Distress management. Volume 1.2015. Retrieved from http://www. nccn.org/professionals/physician_gls/PDF/distress.pdf

Patterson, W., Dohn, H., Bird, J., \& Patterson, G. (1983). Evaluation of suicide patients: The SAD PERSONS scale. Psychosomatics, 24, 343-349. http://dx.doi.org/10.1016/ S0033-3182(83)73213-5

Ransom, S., Jacobsen, P., \& Booth-Jones, M. (2006). Validation of the Distress Thermometer with bone marrow transplant patients. Psycho-Oncology, 15, 604-612. http:// dx.doi.org/10.1002/pon.993

Recklitis, C. J., Diller, L. R., Li, X., Najita, J, Robison, L. L., \& Zeltzer, L. (2010). Suicide ideation in adult survivors of childhood cancer: A report from the Childhood Cancer Survivor Study. Journal of Clinical Oncology, 28, 655-661. http://dx.doi.org/10.1200/JCO.2009.22.8635

Rhondali, W., Perceau, E., Berthiller, J., Saltel, P., Trillet-Lenoir, V., Tredan, O.,...Filbet, M. (2012). Frequency of depression among oncology outpatients and association with other symptoms. Supportive Care in Cancer, 20, 2795-2802. http://dx.doi.org/10.1007/s00520-012-1401-3

Roth, A., \& Levenson, J. (2015). Psychiatric emergencies. In Holland, J. C., Golant, M., Greenberg, D. B., Hughes, M. K., Levenson, J. A., Loscalzo, M. J., \& Pirl, W. F., PsychoOncology: A quick reference on the psychosocial dimensions of cancer symptom management (2nd Ed, pp 37-46). New York, NY: Oxford Press.

Shneidman, E. (1985). Definition of suicide. Retrieved from http://www.suicidepreventionlifeline.org/gethelp.aspx accessed 2/4/2014

Tang, G. X., Yan, P. P., Yan, C. L., Fu, B., Zhu, S. J., Zhou, L. Q.,...Lei, J. (2015). Determinants of suicidal ideation in gynecological cancer patients. Psycho-Oncology, June 22 (e-pub ahead of print).

Trzepacz, P., \& Baker, R. (1993). Thought process, thought content, and perception. In The Psychiatric Mental Status Examination, (pp 82-120). New York, NY: Oxford University Press.

Turaga, K. K., Malafa, M. P., Jacobsen, P. B., Schell, M. J., \& Sarr, M. G. (2011). Suicide in patients with pancreatic cancer. Cancer, 117, 642-647. http://dx.doi.org/10.1002/ cncr. 25428

Urban, D., Rao, A., Bressel, M., Neiger, D., Solomon, B., \& Mileshkin, L. (2013). Suicide in lung cancer: Who is at risk? Chest, 144, 1245-1252. http://dx.doi.org/10.1378/ chest.12-2986

Valente, S. M. (2010). Oncology nurses' knowledge of suicide evaluation and prevention. Cancer Nursing, 33, 290-295. http://dx.doi.org/10.1097/NCC.0b013e3181cc4f33

Walker, J., Holm Hansen, C., Martin, P., Sawhney, A., Thekkumpurath, P., Beale, C.,...Sharpe, M. (2013). Prevalence of depression in adults with cancer: A systematic review. Annals of Oncology, 24, 895-900. http://dx.doi. org/10.1093/annonc/mds575

Ward, K. K., Roncancio, A. M., \& Plaxe, S. C. (2012). Women with gynecologic malignancies have a greater incidence of suicide than women with other cancer types. Suicide and Life-Threatening Behavior, 43, 109-115. http://dx.doi. org/10.1111/sltb.12002 